\title{
Introduction of triage. An experience of a triage nurse in a tertiary centre in Japan
}

\author{
Shinobu Tsuge ${ }^{1}$, Takahiro Shinagawa ${ }^{1}$, Kumi Hara ${ }^{2}$, Akio Aihara ${ }^{3}$ \\ 1 ICU Nurse, ICU Fujita Health University, Banbuntane Houtokukai Hospital, \\ Nagoya, JAPAN. \\ ${ }^{2}$ ICU Head Nurse, ICU Fujita Health University, Banbuntane Houtokukai \\ Hospital, Nagoya, JAPAN. \\ ${ }^{3}$ Nursing Director, Nursing Director Chamber, Fujita Health Univesity \\ Banbuntane Hotokukai Hospital, Nagoya, JAPAN.
}

\begin{abstract}
Emergency medical treatment in Japan is subject to jurisdiction by the Fire Department. Triage, by definition, is a dynamic process, as the patient's status can change rapidly. Triage is very important for Japan, where emergency patients are on the rise. The role of triage nurse is also important. That will improve the life-saving rate of emergency patients and improve the reversion to society.
\end{abstract}

\section{INTRODUCTION}

Emergency medical treatment in Japan is subject to jurisdiction by the Fire Department. Patients being transported by ambulance will be treated as soon as they arrive at the hospital, Japanese ambulance can be requested for free. In recent years, the rate of emergency vehicle dispatch and emergency patients tend to increase year by year.Triage was introduced to Japan so that medical treatment can be provided to patients who really need urgent.

\section{HISTORY OF TRIAGE}

Triage, by definition, is a dynamic process, as the patient's status can change rapidly. Patients may enter the triage stream at any point1. Urgency scales of the world are being developed in the United States in 1994, Australia in 1993 and Canada in 19953. Since around 2012, operation of JTAS became popular, and it was introduced in many hospitals. Our hospital is an emergency designated hospital.

\section{JTAS (JAPAN TRIAGE AND ACUITY SCALE) [4]}

Japan focused on CTAS (Canadian Triage and Acuity Scale) 2 in Canada. CTAS is a highly credible scale that is progressing in North America, Asia and Europe. Japan developed and introduced JTAS based on CTAS. Emergency patients such as brain surgery diseases and cardiovascular diseases are 8507 in one year in Japan [5]. We aimed at improving the

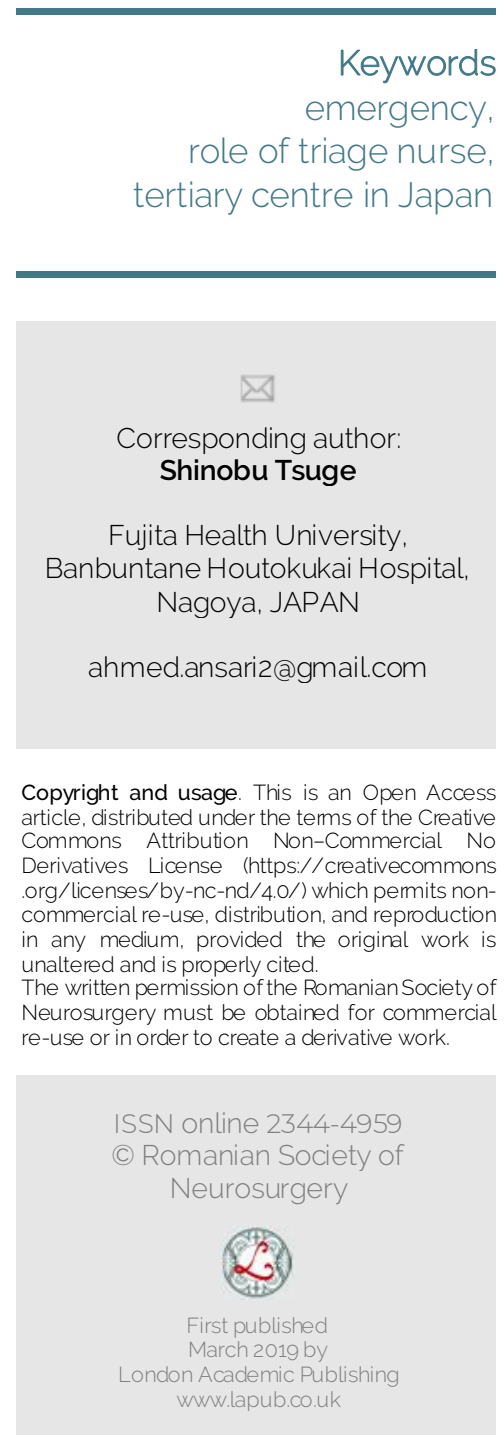


the life-saving rate of our hospital. Therefore, from 2018 triage was introduced.

\section{Components of JTAS \\ Pre-hospital treatment}

As a pre-hospital treatment, there are doctors, car and doctor helicopter. The emergency system in Japan, ambulance and walking patients are treated in the same place. The emergency medical system in Japan is different for each facility

Patients who go to an emergency hospital are patients with mild to severe cases and urgent cases. Among them, as many as $1 \%$ of the patients who walked into the hospital waiting for a sudden change are hidden. There is a danger of missing the patient's life crisis if you are consulting in order of acceptance. Moderate emergency patients are accepted for 24 hours.

\section{Triage method [6]}

Triage will walk to the patient who come to the hospital, the triage nurse will receive the patient.

1. Triage fast touch. After reception, the nurse first responds, at that time, she judges the severity and urgency is necessary or not. If it is an emergency, she starts the treatment immediately. In case of infectious diseases, patients should be isolated.

2. We ask for chief complaints, followed by vital sign measurements, interview, objective findings, etc and the patient is judged according to JTAS level. Patient is asked to wait in the waiting room or monitoring room if monitoring is necessary.

3.After triage, I will consult the patient, when the turn comes

\section{Triage nurse}

A nurse performing a triage is called a triage nurse there are 30 nurses involved in triage. Nurses' years of experience ranged from 5 to 30 years. In order to introduce triage, it was necessary to confirm the ability of the nurse. What is sought are medical knowledge, first-aid skills, cooperation with other occupations, judgment.

\section{Training for triage}

In introducing triage, I confirmed the triage knowledge of the nurse many nurses do not know hospital triage. Depending on the years of experience, there is a difference in ability to do triage. Training was given based on:

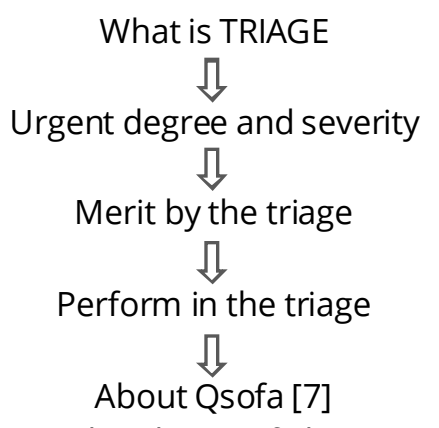

(Quick sepsis related organ failure assessement)

\section{CONCLUSIONS}

Triage is very important for Japan, where emergency patients are on the rise. Among the medical staff, fast touch to the patient is triage nurse, who will improve the life-saving rate of emergency patients and improve the reversion to society.

TABLE 1

\begin{tabular}{|l|l|l|}
\hline & Work site & Job Description \\
\hline $\begin{array}{l}\text { Intensive } \\
\text { care type }\end{array}$ & ICU & $\begin{array}{l}\text { Intensive care of } \\
\text { severely hospitalized } \\
\text { patients }\end{array}$ \\
\hline ER type & ER & $\begin{array}{l}\text { All emergency } \\
\text { medical examination }\end{array}$ \\
\hline $\begin{array}{l}\text { Each } \\
\text { department- } \\
\text { type } \\
\text { collaborative } \\
\text { type }\end{array}$ & $\begin{array}{l}\text { From ER } \\
\text { to ward }\end{array}$ & $\begin{array}{l}\text { Treatment from initial } \\
\text { care to ward }\end{array}$ \\
\hline
\end{tabular}

TABLE 1

\begin{tabular}{|l|l|}
\hline Level 1 & Resuscitation: immediate treatment \\
\hline Level 2 & Emergency: Rapid treatment \\
\hline Level 3 & $\begin{array}{l}\text { Semi-Emergency: First-aid measures } \\
\text { may be necessary }\end{array}$ \\
\hline Level 4 & $\begin{array}{l}\text { Low Emergency: Treatment within 1 } \\
\text { hour to 2 hours }\end{array}$ \\
\hline Level 5 & Non-Emergency: No Urgency \\
\hline
\end{tabular}

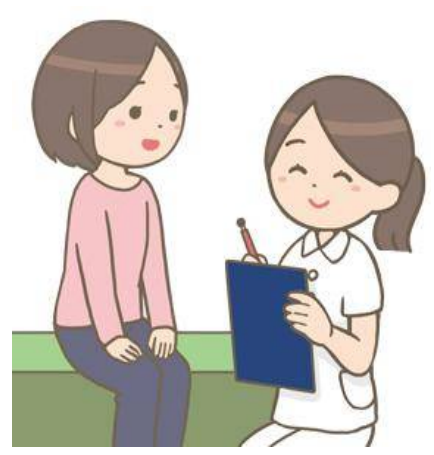

FIGURE 1

Fast touch.

Assessment of severe complaints 


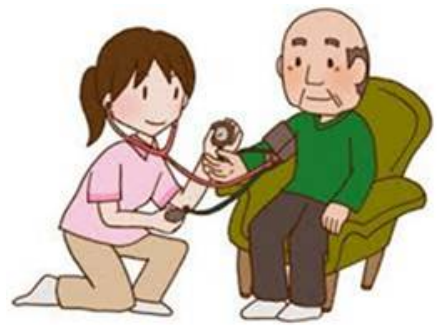

FIGURE 2

Vital sign

measurement

Medical interview

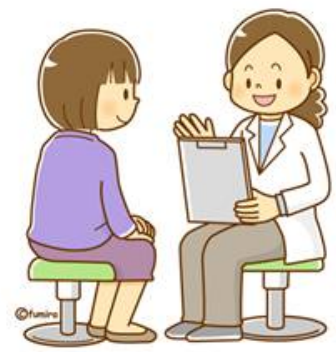

3. Health System Organization and Governance in Canada and Australia: A Comparison of Historical Developments, Recent Policy Changes and Future Implications. Donald J. Philippon et al.

4. A study on the effect of introducing JTAS in emergency outpatient (JTAS in the emergency room). Toru Koyama (Toru Oyama) et al.

5. Kyoto University Hospital GUIDANC E 2015.

6. Gilboy N, Tanabe T, Travers D, Rosenau AM. Emergency Severity Index (ESI): A Triage Tool for Emergency Department Care, Version 4. Implementation Handbook 2012 Edition. AHRQ Publication No. 12-0014. Rockville, MD. Agency for Healthcare Research and Quality. November 2011.

7. Utility of quick sepsis-related organ failure assessment (qSOFA) to predict outcome in patients with pneumonia. Müller M, Guignard V, Schefold JC, Leichtle AB, Exadaktylos AK, Pfortmueller CASendtoPLoS One. 2017 Dec 21;12(12): e0188913. doi: 10.1371/journal.pone.0188913. eCollection 2017.

\section{REFERENCES}

1. Evolution of triage systems, lain Robertson - Steelet al, Emerg Med Jv.23(2); 2006 Feb.

2. Prehospital Canadian Triage \& Acuity Scale Prehospital CTAS Paramedic Guideby Joan, Burton, 7. 